\title{
Ictal Onset and Spreading of Seizures of Parietal Lobe Origin
}

\author{
Tatsuo AKIMURA, Masami FUjII, Makoto IDEGUCHI, Koichi YOSHIKAWA, \\ and Michiyasu SUZUKI
}

Department of Neurosurgery, Yamaguchi University School of Medicine, Ube, Yamaguchi

\begin{abstract}
The characteristics of seizures associated with parietal lobe epilepsy were investigated in six consecutive patients with medically intractable epilepsy due to parietal lobe lesions. Intracranial electrode recordings were retrospectively reviewed to investigate the seizure onset symptoms and spreading patterns associated with the disorder. All six patients underwent implantation of subdural or depth electrodes and subsequent video/electroencephalography monitoring. Common symptoms included motionless stare, contralateral eye deviation, and head turn. Tonic posturing, contralateral sensory disturbance, and motor weakness were also seen. Asymmetrical generalized tonic and clonic seizures were seen in all six patients. All seizure activities began in the parietal lobe harboring the lesions, and then spread immediately to the adjacent lobes in most seizures, where the clinical symptoms were produced. The parietal lobe is a pure generator of seizures, whereas most clinical symptoms originate from adjacent lobes following seizure onset. No apparent specific symptoms other than sensory disturbance arising from the parietal lobe proper were recognized. Regardless of clinical symptoms, the seizure onset occurred in the parietal lobe harboring the lesion.
\end{abstract}

Key words: parietal lobe epilepsy, seizure onset, seizure spread

\section{Introduction}

Parietal lobe epilepsy is relatively rare compared to temporal or frontal lobe epilepsy. ${ }^{3)}$ The clinical features of seizures of parietal lobe origin are not yet fully understood. ${ }^{6,16,18)}$ The parietal lobe occupies a relatively smaller volume of the brain than the temporal or frontal lobe, and is very closely connected with the adjacent lobes. The function of the parietal lobe is also more complex, which exacerbates the difficulty in understanding the symptoms of epilepsy of parietal lobe origin.

The present study reviewed six consecutive cases of medically intractable epilepsy of parietal lobe origin and investigated the seizure onset and spread patterns, as well as the electroencephalographic (EEG) patterns associated with seizure onset, such as spikes, sharp waves, fast activities, and the pattern of attenuation (i.e., flattening of the EEG). ${ }^{2)}$

\section{Materials and Methods}

Six consecutive patients with intractable parietal

Received May 2, 2002; Accepted May 28, 2003 lobe epilepsy were treated by implantation of subdural electrodes followed by epilepsy surgery (Table 1). All patients had structural lesions in the parietal lobe, which were identified by magnetic resonance (MR) imaging.

Subdural electrodes were placed on the area over the lesion and the surrounding cortex. If lateralization of the ictal symptoms was uncertain and involvement of the temporal lobes was suspected, electrodes were also placed in the contralateral hemispheres and mesial temporal lobes. Depth electrodes were inserted into the bilateral temporal lobes in one patient. At least three or more habitual seizures were observed with video/EEG recording for each patient. Seizure onset was carefully identified by video and EEG monitoring. Attenuation of the EEG was defined as seizure activity characterized by diffuse, low-voltage, fast activity of $<25 \mu \mathrm{V}$ and frequently $>15 \mathrm{~Hz}$, or by diffuse flattening of the EEG without visible fast activity. ${ }^{1)}$

All patients underwent resection of the epileptogenic cortices and the lesion, if possible. The extent of cortical resection was determined by subdural electrode recording and cortical stimulation as well as intraoperative electrocorticography (ECoG). The 
Table 1 Summary of the clinical characteristics

\begin{tabular}{|c|c|c|c|c|c|c|c|c|c|}
\hline $\begin{array}{l}\text { Case } \\
\text { No. }\end{array}$ & $\begin{array}{l}\text { Age (year)/ } \\
\text { Sex }\end{array}$ & $\begin{array}{l}\text { Seizure } \\
\text { type }\end{array}$ & $\begin{array}{c}\text { Duration } \\
\text { (year) }\end{array}$ & $\begin{array}{l}\text { MR imaging } \\
\text { findings }\end{array}$ & $\begin{array}{c}\text { Phase II } \\
\text { onset }\end{array}$ & $\begin{array}{c}\text { Symptomatic } \\
\text { lobes }\end{array}$ & Surgery & $\begin{array}{l}\text { Follow up } \\
\text { (year) }\end{array}$ & Outcome* \\
\hline 1 & $35 / F$ & $\begin{array}{l}\text { PS, CPS, } \\
\text { rare GTC }\end{array}$ & 26 & $\begin{array}{l}\text { hyperintensity } \\
\text { on FLAIR/lt } \\
\text { parietal }\end{array}$ & lt parietal & $\begin{array}{l}\text { lt parietal, } \\
\text { frontal }\end{array}$ & $\begin{array}{l}\text { cortical } \\
\text { resection } \\
\text { and MST }\end{array}$ & 6 & Class I \\
\hline 2 & $12 / \mathrm{M}$ & CPS, GTC & 4 & $\begin{array}{l}\text { porencephaly/ } \\
\text { lt parieto- } \\
\text { occipital }\end{array}$ & lt parietal & lt temporal & $\begin{array}{l}\text { cortical } \\
\text { resection }\end{array}$ & 5.5 & Class I \\
\hline 3 & $38 / \mathrm{M}$ & CPS, GTC & 35 & $\begin{array}{l}\text { encephalo- } \\
\text { malacia/bil } \\
\text { parietal }\end{array}$ & rt parietal & $\begin{array}{l}\text { rt frontal, } \\
\text { parietal, } \\
\text { SMA }\end{array}$ & $\begin{array}{l}\text { cortical } \\
\text { resection } \\
\text { and MST }\end{array}$ & 7 & Class III \\
\hline 4 & $38 / \mathrm{M}$ & $\begin{array}{l}\text { CPS, } \\
\text { rare GTC }\end{array}$ & 23 & $\begin{array}{l}\text { hemosiderin } \\
\text { deposit/lt } \\
\text { mesial } \\
\text { parietal }\end{array}$ & lt parietal & rt temporal & $\begin{array}{l}\text { cortical } \\
\text { resection } \\
\text { and } \\
\text { lesionectomy }\end{array}$ & 7.5 & Class III \\
\hline 5 & $23 / \mathrm{F}$ & CPS, GTC & 23 & $\begin{array}{l}\text { hyperintensity } \\
\text { on FLAIR/bil } \\
\text { parietal }\end{array}$ & rt parietal & $\begin{array}{l}\text { rt frontal, } \\
\text { temporal }\end{array}$ & $\begin{array}{l}\text { cortical } \\
\text { resection } \\
\text { and MST }\end{array}$ & 2 & Class I \\
\hline
\end{tabular}

${ }^{*}$ According to Engel's classification. ${ }^{4)}$ CPS: complex partial seizure, FLAIR: fluid-attenuated inversion recovery, GTC: generalized tonic-clonic convulsion, MR: magnetic resonance, MST: multiple subpial transection, PS: partial seizure, SMA: supplementary motor area.

epileptogenic zone was defined by the area of initial EEG changes, such as attenuation, spikes, spike waves, polyspike waves, sharp waves, and sharply contoured activities. Cortical resection was avoided and multiple subpial transection (MST) ${ }^{12)}$ was performed if neurological symptoms appeared during preoperative cortical stimulation of the epileptogenic zone. Intraoperative ECoG was performed after cortical resection and disappearance of seizure activities was confirmed. MST of the surrounding cortices was also carried out if the intraoperative ECoG showed active spikes after cortical resection.

Assessment of the outcomes was made according to Engel's classification (Class I, free of disabling seizures; Class II, rare disabling seizures; Class III, worthwhile improvement; Class IV, no worthwhile improvement). ${ }^{4}$

\section{Representative Cases}

Case 2: A 12-year-old boy presented with a history of complex partial seizures since the age of 8 years. Habitual seizures included motionless stare, right eye deviation, and right head turn with rare generalized tonic-clonic convulsion. The phase I study revealed that his seizures involved predominantly the left hemisphere, and were mostly parieto-occipital lobes in origin. No attenuation of scalp EEG recordings was recognized. MR imaging revealed the presence of a porencephalic cyst in the left parieto-occipital region. The surrounding brain

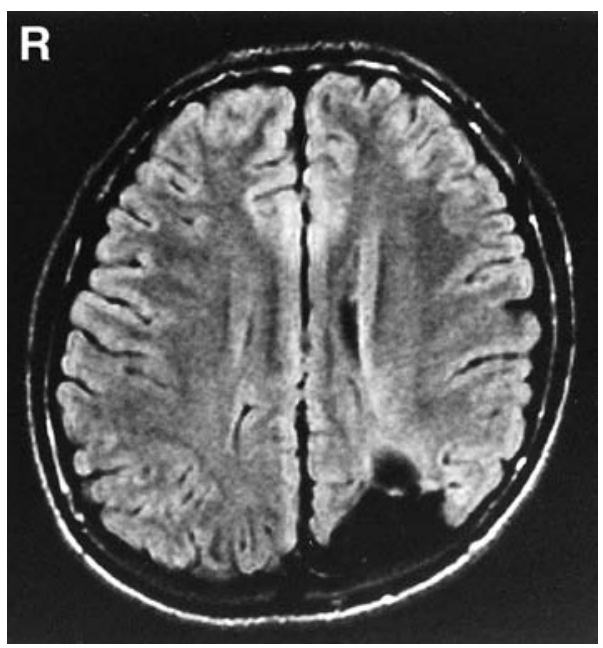

Fig. 1 Case 2. Magnetic resonance image with fluid-attenuated inversion recovery sequence (time to repetition/time to echo $9000 / 119 \mathrm{msec}$, time to inversion $2200 \mathrm{msec}$ ) showing porencephaly in the left parietal lobe.

region was hyperintense on fluid-attenuated inversion recovery (FLAIR) images (Fig. 1). No apparent hippocampal sclerosis was recognized.8) The Wada test showed that the left hemisphere was dominant.

The patient underwent phase II video/EEG monitoring with subdural electrodes. Three of four recorded habitual seizures originated in the cortex 


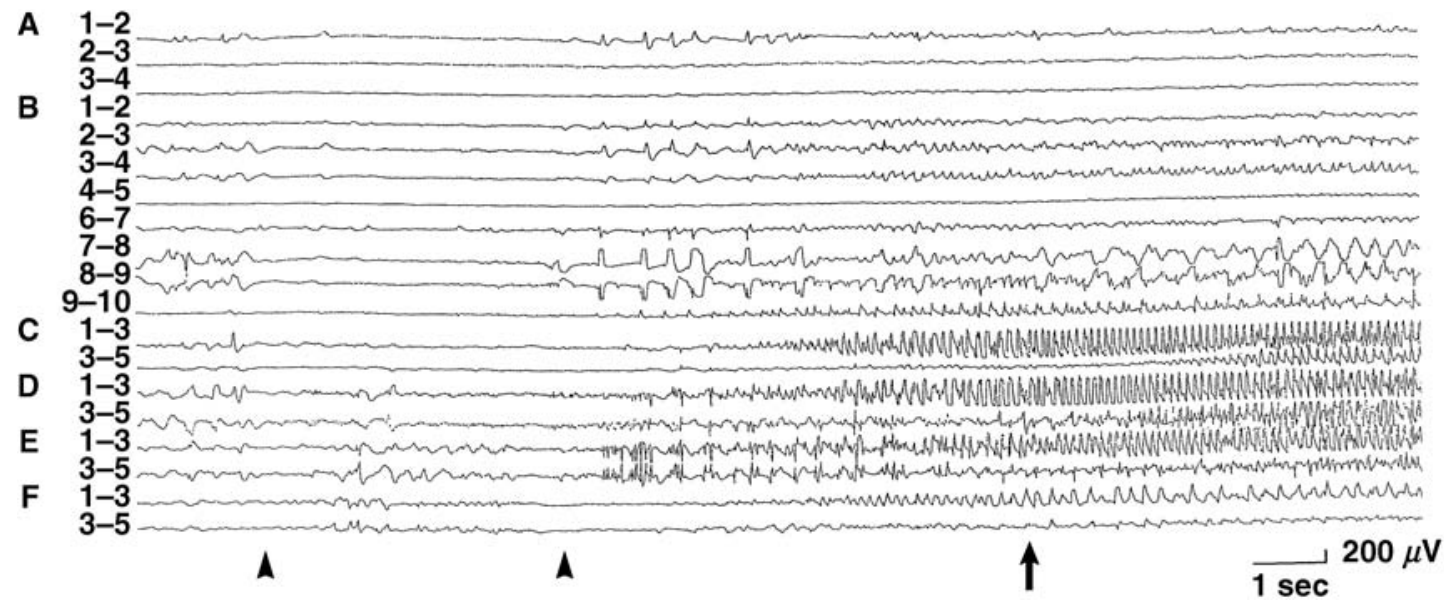

Fig. 2 Case 2. Subdural electrode recordings of the seizure onset. Flattening of the electroencephalography occurred first in the mesial parietal lobe $(A, B)$ and then in the dorsolateral parietal lobe (C-E) (arrowheads). Seizure activities first appeared in the mesial parietal strips $(B, D, E)$ and then spread to the temporal lobe (F). Clinical seizure began after spreading of the seizure activity to the temporal lobe (arrow). A: left anterior mesial parietal strip, B: left posterior mesial parietal, C-E: left dorsolateral parietal, F: left temporal.

of the left parieto-occipital lobe, which included the medial border of the porencephalic cyst, and one seizure originated in the mesial parietal cortex adjacent to the porencephalic cyst, although the clinical presentation was the same as for the seizures of lateral parietal onset (Fig. 2). Two of the four habitual seizures exhibited an EEG attenuation pattern that lasted for 3 seconds, and preceded onset of the clinical seizure by 7-20 seconds (as evidenced by symptoms such as eye deviation and stare). The attenuation pattern involved all leads placed in the ipsilateral hemisphere. In one of the seizures, onset in the lateral parietal lobe was not suppressed during the period of EEG attenuation, and showed beta buzzing, sharply-contoured activities, and slow waves.

Excision of the cortex over the porencephalic cyst and surrounding brain was performed. Histological examination revealed gliosis. This patient has been seizure free since surgery (Class I).

Case 4: A 38-year-old man had a history of complex partial seizures since the age of 15 years. His habitual seizures included symptoms of motionless stare, oral automatism, and loss of consciousness. This patient had lost his fingers as a result of a burn injury, which he sustained during a complex partial seizure. $\mathrm{T}_{2}$-weighted $\mathrm{MR}$ imaging revealed an extremely hypointense lesion suggesting hemosiderin deposits in the left mesial parietal lobe (Fig. 3). Video/EEG monitoring with scalp electrodes revealed interictal spikes in the bilateral temporal lobes, but the seizure onset was not identified be-

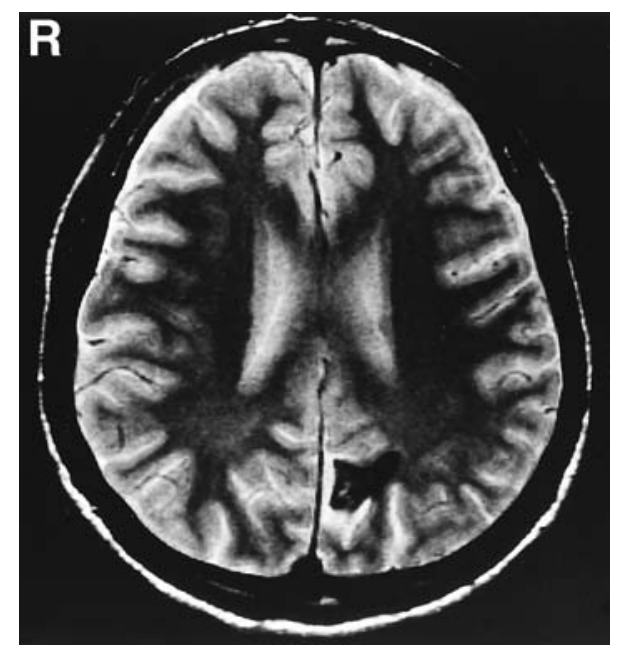

Fig. 3 Case 4 . $T_{2}$-weighted magnetic resonance image (time to repetition/time to echo $\mathbf{5 0 0 0 / 1 9}$ msec) showing a hypointense mass in the left mesial parietal lobe.

cause of artifacts caused by masticatory movements of the mouth. No attenuation pattern was observed.

He underwent implantation of subdural electrodes covering the left parietal and bilateral mesial temporal lobes. His seizures began in the left mesial parietal lobe and spread over the ipsilateral temporal lobe within 10 seconds (Fig. 4). An attenuation pattern was observed in the left mesial parietal grids during all four of the seizures captured during the phase II study. This attenuation pattern preceded 


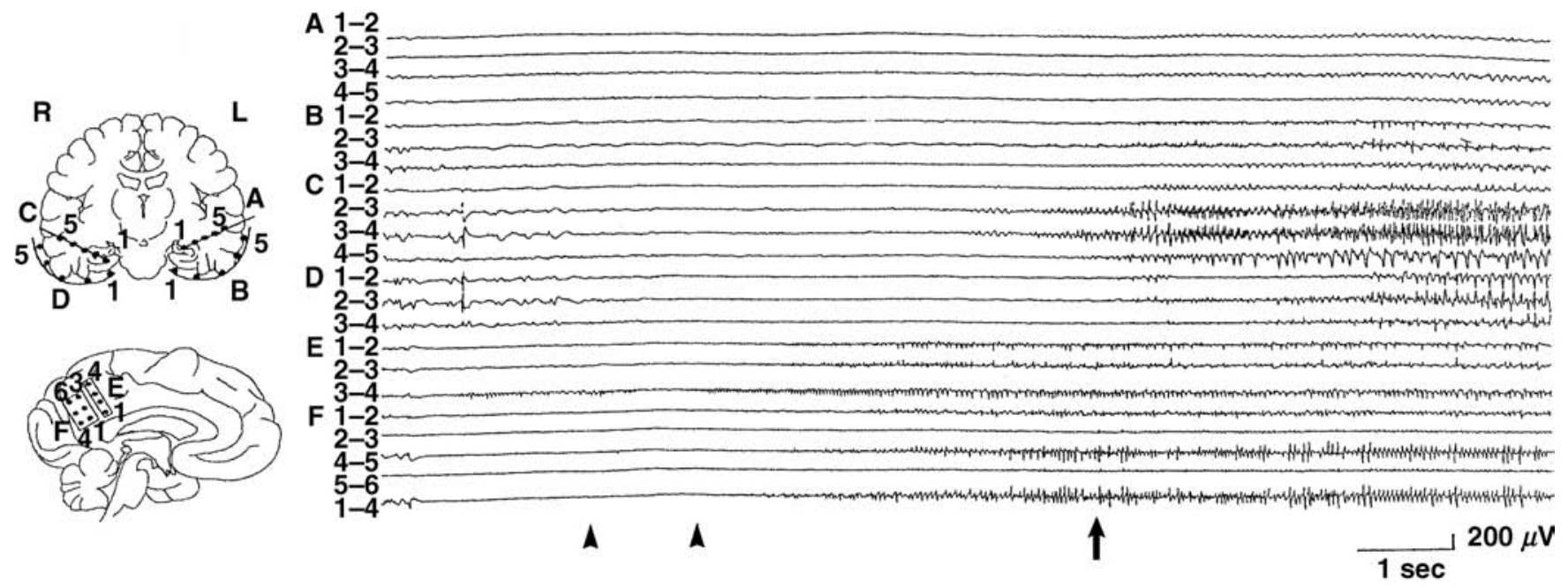

Fig. 4 Case 4. Subdural and depth electrode recordings of the seizure onset. Seizure activities first appeared in the left mesial parietal strip and then the right medial temporal depth electrode. Clinical seizure began after the seizure activity spread to the temporal lobe. Flattening of the electroencephalography (arrowheads) preceded the clinical seizure onset (arrow).

seizure onset by 10 seconds, lasted until the seizure spread to the ipsilateral temporal lobe, and coincided with a period of motionlessness. The duration of the flattening of the EEG was shortest in the seizure onset zone. Continuous spike discharges followed the diffuse flattening of the EEG. Approximately 10 seconds after seizure onset in the left parietal lobe, seizure activities spread to the contralateral temporal lobe. Automatism began after seizure spread to the temporal lobe.

A left parietal vascular lesion associated with a thrombosed arteriovenous malformation and the surrounding cortex were removed, which immediately reduced the frequency of seizures suffered by the patient (Class II), but later deteriorated to Class III. MR imaging performed 4 years postoperatively revealed a hyperintense lesion around the resected area (FLAIR images) and right hippocampal atrophy.

\section{Results}

\section{Seizure outcome}

The follow-up period ranged from 2 years to 10 years (mean 6.3 years). Three patients became seizure-free, one patient experienced Class II changes, one patient experienced Class III changes, and one patient experienced Class II changes in the first postoperative year, then deteriorating to Class III.

\section{Clinical seizure patterns}

Asymmetrical generalized tonic-clonic seizures were seen in all patients. Seizures including motionless stare followed by eye deviation and head turn were observed in four patients (Cases 2, 4, 5, and 6). Case 4 predominantly exhibited symptoms mimicking temporal lobe epilepsy, such as motionless stare, oral automatism, and autonomic symptoms. Three patients had clinical symptoms originating from the rolandic cortices, such as sensory disturbance and involuntary movement of the extremities (Cases 1, 3, and 6). The seizures of Case 3, who experienced symptoms such as eye deviation, head turn, and facial grimace, were also similar to seizures of frontal lobe origin. ${ }^{14,17)}$ Sudden tonic posturing of this patient suggested involvement of the supplementary motor area. ${ }^{13)}$ No symptoms arising from the parietal lobe proper were observed.

\section{Scalp EEG}

The lesions could not be localized in all patients with continuous video/scalp EEG recordings because of electromyographic (EMG) artifacts, but lateralization was obtained in five of the six patients. One patient exhibited solitary spike discharges in the right central electrode, and one patient showed bilateral temporal spikes, but EMG artifacts obscured the ictal onset pattern. Diffuse electrodecremental patterns were only observed with any frequency in Case 3.

\section{Subdural electrode recordings}

Intracranial EEG recording detected seizure onset patterns including spikes, spike waves, polyspike waves, sharp waves, and sharply contoured activi- 


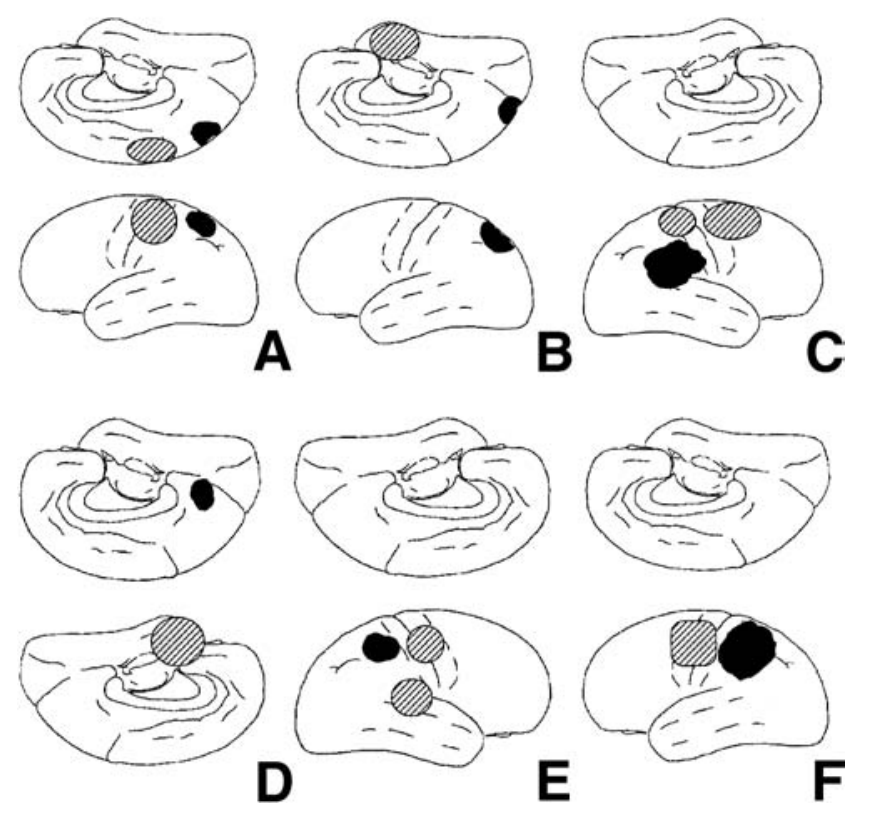

Fig. 5 Shematic representation of the lesions (hatched areas) and the seizure spread to the cortices (shaded areas). A: Case 1, B: Case 2, C: Case 3, D: Case 4, E: Case 5, F: Case 6.

ties. ${ }^{2)}$ Three of the six patients with seizures of parietal lobe origin exhibited an attenuation pattern just prior to seizure onset or in the early part of a complex partial seizure. Case 3, who did not exhibit an attenuation pattern in association with seizure in scalp EEG, exhibited attenuation patterns in intracranial electrode recordings.

In Case 1, the seizure onset was in the left parietal lobe, whereas the symptoms originated in the left frontal and parietal lobes. In Case 2, the seizure onset was in the left parietal lobe, whereas the symptoms were produced after involvement of the ipsilateral temporal lobe. In Case 3, the seizure onset was in the right parietal lobe, whereas the symptoms originated in the right frontal and parietal lobes. In Case 4, the seizure onset was in the left parietal lobe and the symptoms occurred when seizure activity spread to the contralateral temporal lobe. In Case 5, the seizure onset was in the right parietal lobe and the symptoms began after spreading to the right frontal and temporal lobes. In Case 6, the seizure onset was in the right parietal lobe and the symptoms originated from the right frontal and parietal lobes. These results are summarized in Table 1.

Schematic representations of the lesions and spread of seizure activities to the lobes are shown in Fig. 5.

Seizure onset zones were always within the area of attenuation. Seizures with preceding attenuation patterns were associated with non-uniform EEG waveforms. Some seizures began with low-voltage beta activity and flattening of the EEG in the surrounding brain, whereas others started with localized rhythmic spike discharges. All seizure activities began within the parietal lobe harboring the lesion and, in most cases, spread immediately to the adjacent lobes.

\section{Discussion}

The seizures were controlled fairly well by cortical excision and lesionectomy within the parietal lobe in all six patients, regardless of the direction of spread of seizure activities and clinical symptoms. These results are consistent with previous findings. ${ }^{18)}$ Most seizures were confirmed to be of parietal lobe origin. Encephalomalacia had involved the ipsilateral frontal lobe and part of the residual seizures would be of frontal lobe origin in Case 3 . MR imaging taken 4 years postoperatively revealed right hippocampal atrophy in Case 4, suggesting a secondary focus of the seizure. Clinical seizures began after spread of epileptiform activity to the temporal lobe (Cases 2, 4, and 5) or to the frontal lobe (Case 3).

No symptoms originated from the parietal lobe proper except for abnormal sensations. Eye deviation and head turn were the most common symptoms, suggesting involvement of the frontal lobe (dorsolateral frontal), ${ }^{17)}$ supplementary motor area, and occipital lobe. ${ }^{19)} \mathrm{A}$ review of 82 patients found that most exhibited motor phenomena including head deviation, posturing, or focal clonic activity. ${ }^{16)}$ In Case 2, the ictal symptoms appear to have occurred after activation of the temporal lobe. The clinical symptoms were the same whether seizure activities began in the mesial parietal or dorsolateral parietal lobe. In Case 4, the clinical symptoms began after involvement of the contralateral temporal lobe. Therefore, the parietal lobe appears to be an epileptogenic zone rather than a symptomatogenic zone. Ictal spread to the frontal, supplementary motor area or temporo-limbic areas were often observed. ${ }^{16)}$

Three of our six patients with seizures of parietal lobe origin exhibited an attenuation pattern just prior to seizure onset or in the early part of a complex partial seizure. Attenuation patterns represent the most common EEG expression of infantile spasms occurring in West syndrome. ${ }^{10,11)}$ Diffuse flattening of scalp EEGs may represent generalized seizure, possibly of brainstem origin. ${ }^{5}$ Thirty-nine patients had diffuse electrodecremental ictal patterns on scalp EEGs in addition to seizures of diffuse cortical and brainstem origin. ${ }^{1)}$ Seven of these 
patients underwent placement of subdural electrodes, which observed high-frequency ictal discharges originating in a single frontal lobe. Low-voltage, high-frequency discharges were detected over all implanted electrodes for 1-2 seconds, followed by rhythmical $10-$ to $25-\mathrm{Hz}$ spikes over a variable number of electrodes placed over the frontal and temporal regions at the start of all seizures.

Attenuation patterns (i.e., suppression of EEG activity) could be produced by cortical stimulation in certain specific motor areas. ${ }^{15)}$ Suppressor effects were most commonly seen in the periamygdaloid anterior temporal region and the supplementary motor area. Scattered suppressor responses were also seen in the lateral surface of the intermediate frontal region and scattered points in the parietal and occipital regions. If seizure activities involve these regions, flattening of the EEG may occur. ${ }^{7)}$

The ictal pattern of neocortical epilepsy was localized to 2-9 subdural electrodes, and was characterized by very low-voltage and high-frequency rhythmic activity, which was considered to be an attenuation pattern. ${ }^{9}$ A slow-rising negative direct current (DC) potential was seen in a more restricted area and occurred 1-10 seconds before the initial ictal EEG discharges in two of three patients. These findings are quite similar to our results. The point of the DC shift might be related to the origin of flattened EEG activity. The arousal response, which originates from the thalamus and then spreads to the cortex, may be another cause of the flattening of EEG activity that occurs prior to a seizure. ${ }^{14)}$ Flattening of EEG activity preceded clinical seizure onset, but did not localize the seizure onset zone.

\section{References}

1) Arroyo S, Lesser RP, Fisher RS, Vining EP, Krauss GL, Bandeen-Roche K, Hart J, Gordon B, Uematsu S, Webber R: Clinical and electroencephalographic evidence for sites of origin of seizures with diffuse electrodecremental pattern. Epilepsia 35: 974-987, 1994

2) Blume WT, Young GB, Lemieux JF: EEG morphology of partial epileptic seizures. Electroencephalogr Clin Neurophysiol 57: 295-302, 1984

3) Boon PA, Williamson PD, Fried I, Spencer DD, Novelly RA, Spencer SS, Mattson RH: Intracranial, intraaxial, space-occupying lesions in patients with intractable partial seizures: an anatomoclinical, neuropsychological, and surgical correlation. Epilepsia 32: 467-476, 1991

4) Engel J Jr: Outcome with respect to epileptic seizures, in Engel J Jr (ed): Surgical Treatment of the Epilepsies, ed 2. New York, Raven Press, 1993, pp 609-621
5) Gastaut H, Roger J, Ouahchi S, Timsit M, Broughton R: An electro-clinical study of generalized epileptic seizures of tonic expression. Epilepsia 4: 15-44, 1963

6) Geier S, Bancaud J, Talairach J, Bonis A, HossardBouchaud H, Enjelvin M: Ictal tonic postural changes and automatisms of the upper limb during epileptic parietal lobe discharges. Epilepsia 18: 517-524, 1977

7) Gloor P: Contributions of electroencephalography and electrocorticography to the neurosurgical treatment of the epilepsies, in Purpula DP, Penry JK, Walter RD (eds): Neurosurgical Management of the Epilepsies. Advances in Neurology, vol 8. New York, Raven Press, 1975, pp 59-104

8) Ho SS, Kuzniecky RI, Gilliam F, Faught E, Bebin M, Morawetz R: Congenital porencephaly: MR features and relationship to hippocampal sclerosis. AJNR Am J Neuroradiol 19: 135-141, 1998

9) Ikeda A, Terada K, Mikuni N, Burgess RC, Comair Y, Taki W, Hamano T, Kimura J, Luders HO, Shibasaki $\mathrm{H}$ : Subdural recording of ictal DC shifts in neocortical seizures in humans. Epilepsia 37: 662-674, 1996

10) Kellaway P, Crawley JW, Kagawa N: A specific electroencephalographic correlate of convulsive equivalent disorders in children. J Pediatr 55: 582-592, 1959

11) Kellaway P, Hrachovy RA, Frost JD, Zion T: Precise characterization and quantification of infantile spasms. Ann Neurol 6: 214-218, 1979

12) Morrell F, Whisler WW, Bleck TP: Multiple subpial transection: a new approach to the surgical treatment of focal epilepsy. J Neurosurg 70: 231-239, 1989

13) Morris HH, Dinner DS, Luders H, Willie E, Kramer R: Supplementary motor seizures: clinical and electroencephalographic findings. Neurology 38: 1075-1082, 1988

14) Niedermeyer E: Epileptic seizure disorders, in Niedermeyer E, Lopes Da Silva F (eds): Electroencephalography. Baltimore, Williams \& Wilkins, 1993, pp 461-564

15) Penfield W, Jasper H: Epilepsy and the Functional Anatomy of the Human Brain. Boston, Little \& Brown, 1954, pp 692-738

16) Salanova V, Andermann F, Rasmussen T, Olivier A, Quesney LF: Parietal lobe epilepsy. Clinical manifestations and outcome in 82 patients treated surgically between 1929 and 1988. Brain 118: 607-627, 1995

17) Wieser HG, Swartz BE, Delgado-Escueta AV, Bancaud J, Walsh GO, Malnando H, Saint Hilaire JM: Differentiating frontal lobe seizures from temporal lobe seizures, in Chauvel $\mathrm{P}$, Delgado-Escueta AV (eds): Advances in Neurology, vol 57. New York, Raven Press, 1992, pp 267-285

18) Williamson PD, Boon PA, Thadani VM, Darcey TM, Spencer DD, Spencer SS, Novelly RA, Mattson RH: Parietal lobe epilepsy: diagnostic considerations and results of surgery. Ann Neurol 31: 193-201, 1992

19) Wyllie E, Luders H, Morris HH, Lesser RP, Dinner DS: The lateralizing significance of versive head and eye movements during epileptic seizures. Neurology 
36: 606-611, 1986

Address reprint requests to: T. Akimura, M.D., Department of Neurosurgery, Yamaguchi University School of Medicine, 1-1-1 Minamikogushi, Ube, Yamaguchi 755-8505, Japan.

e-mail: tatsuaki@po.cc.yamaguchi-u.ac.jp

\section{Commentary}

Akimura and colleagues provide an interesting account of seizure expression and intracranial electroencephalographic recordings in six patients with parietal lobe structural lesions and seizure onset. Parietal lobe seizure disorders are considerably less well understood than those of temporal or frontal lobe origin, and although the findings from this series are largely consistent with previous reports, its contribution of six additional, well-studied patients to our collective experience with this type of seizure will be appreciated. The investigations in the patients of this series illustrate the utility of intracranial recording and the major role it may play in surgical treatment. The report further documents the kind of success that can be achieved with these patients. The patients in this series had structural lesions identified on MRI, but as more and more epileptic patients with neocortical epilepsy but normal MRI come to attention, the lessons derived from lesional epilepsy experience may enable better patient selection, utilization of intracranial studies, electrode array determination, and eventual resection.

$$
\begin{array}{r}
\text { David W. ROBERTS, M.D. } \\
\text { Section of Neurosurgery } \\
\text { Dartmouth-Hitchcock Medical Center } \\
\text { Lebanon, New Hampshire, U.S.A. }
\end{array}
$$

This article confirms that seizures frequently spread to different areas of the brain producing very diverse symptomatology. The parietal lobe is a highly convergent cortical region and a major network relay for the integration of pathways between the frontal, temporal and occipital lobes. Focal seizures arising from the parietal lobe constitute $5 \%$ to $7 \%$ of focal epilepsies in both lesional and non-lesional series. They may present with positive phenomena of a tingling and "feeling of electricity" which can be confined to a specific region, or may evolve in a jacksonian man- ner. There may be a desire to move a part of the body, or a sensation as if a segment was being moved. The areas most commonly involved are those with the largest cortical representation such as the hand, arm or face. Occasionally an intra-abdominal sensation of sinking, choking or nausea may occur. Formed visual hallucinations are common with visual distortions and elongations (metamorphopsia). Negative phenomena include numbness, feeling that a body part is absent and a loss of awareness of a part or half of the body (asomatognosia). Seizures in the dominant parietal lobe result in a variety of receptive or conductive language disturbances. Similar to occipital lobe onset, partial parietal lobe seizures manifest loss of awareness and automatisms when they spread and involve the temporal lobe; or tonic posturing, often bilateral and asymmetric when they propagate to the frontal region. This varied symptomatology has been previously reported in non-lesional cases, and no significant differences are shown in the present study of lesional parietal lobe epilepsy.

This study addresses the fact that the evaluation of parietal lobe seizures is challenging. The scalp EEG is often poorly localizing or even mislocalizing. Generalized or lateralized ictal patterns are the most common and less than $15 \%$ of the seizures are well localized on surface recordings. Not infrequently interictal epileptiform discharges are multiregional suggesting involvement of cortical areas distant from the epileptogenic zone. The ictal patterns depend on the pathway of propagation and may erroneously suggest an extraparietal lobe origin, such as the frontal or temporal lobes. Also, partial seizures of parietal lobe origin not associated with loss of awareness frequently lack EEG correlates.

The outcome of postoperative patients is related to the complete resection of the epileptogenic zone. The possibility of dual pathology could explain the poor outcome in seizure control in patients with parietal lobe seizures (by EEG and semiology) and atrophy in the mesial temporal structures on imaging studies. These patients eventually need invasive recordings to decide if the seizures arise from the parietal lobe or from the mesial temporal region. Ictal SPECT and PET studies can also be helpful in such cases.

Paul ShKurovich, M.D. and Hans O. LÜDERS, M.D. The Cleveland Clinic Foundation Cleveland, Ohio, U.S.A. 